Article

\title{
The Reality of Light Pollution: A Field Survey for the Determination of Lighting Environmental Management Zones in South Korea
}

\author{
Hong Soo Lim, Jack Ngarambe, Jeong Tai Kim and Gon Kim * \\ Department of Architectural Engineering, Kyung Hee University, Yongin 446-701, Korea; \\ hongsoolim@khu.ac.kr (H.S.L.); ngarajack@khu.ac.kr (J.N.); jtkim@khu.ac.kr (J.T.K.) \\ * Correspondence: gonkim@khu.ac.kr
}

Received: 26 December 2017; Accepted: 29 January 2018; Published: 31 January 2018

\begin{abstract}
Light pollution has been receiving increased attention worldwide. Scientific research has provided convincing evidence that ties artificial lighting to health-related issues. Consequently, the involved parties are now leaned towards the implementation of regulations to help limit the use of artificial lighting. Many countries, together with international organizations, have embarked on setting standards and regulations aimed at halting the excessive and improper usage of artificial lighting, there-by eradicating light pollution and its effects. In Korea, outdoor lighting at night is a common phenomenon. Moreover, as the economic development grows even further, the use of artificial lighting is expected to increase making Korea vulnerable to the adverse effects of artificial lighting. In this study, we discuss the issue of light pollution based on field measurements conducted in Seoul, South Korea. The measurements were undertaken to broaden the understanding and assessment of light pollution. During the investigation, we noted that the most severe forms of light pollution were found in developed urban and densely commercialized areas. Currently, there are ongoing light pollution measurement projects around the entire Korea. It would be informative to see how the rest of South Korea compares to the Capital, Seoul in terms of light pollution levels.
\end{abstract}

Keywords: light pollution; light trespass; glare; lighting zones

\section{Introduction}

Modern artificial lighting can be considered a key achievement in the technology revolution of the past century. However, even though artificial lighting is hugely beneficial to modern society, it still presents significant disadvantages, in the form of pollution, to human health and the ecological wellbeing of the environment. Light or photo pollution can be simply defined as excessive or misdirected artificial lighting. Scientifically, it has been defined as the changes in outdoor natural light levels as a result of artificial lighting [1]. The IDA (International Dark-Sky Association) defines light pollution as the inappropriate or excessive use of artificial lighting [2]. There are also several legal definitions of light pollution. For instance, the Korean government defines light pollution as "any situation where inappropriate use of artificial lighting may interfere with people's health and comfort, or harm the ecological system" [3].

Other than the radical issue of sky glow caused by artificial lighting [4,5], light pollution is also the cause of a number of known ecological concerns. Among the known effects, health issues in humans caused by exposure to artificial lighting at night are the most pressing. To understand how light may affect humans, it is ideal to realize first how light is introduced into the body and how it is used by the body. Light is introduced to the body through the eye. Some of the light is then used for vision whereas the rest of the light mediates in other human biological processes, such as the synchronization of the light and dark cycles. In that context, the effects of light pollution in humans 
can also be divided into 2 categories; the image forming effects and the non-image forming effects. The image forming problems caused by artificial lighting are mostly associated with discomfort and disability glare. Photometric parameters of light have been indicated to be a contributing force to the occurrence of both types of glare; discomfort and disability glare [6]. The non-image forming effects are mainly due to a disrupted circadian rhythm — an internal clock that regulates most of the physiological systems in mammals [7]. The circadian cycle is a complex system that begins in the eye and ends in the pineal gland where melatonin hormone is secreted-a neuro hormone responsible for the rhythmic functioning of the human internal clock. Melatonin is secreted during the dark hours of the night. The peak secretion of melatonin has been reported to be between midnight and 4 a.m. in the morning [8]. Consequently, exposure to light during this period of the day may inhibit the production of melatonin and thus a disruption of the entire circadian cycle. The desynchronization of the circadian rhythm is believed to be the cause of many clinical conditions in humans. It has been linked to simple discomforts such as fatigue [9], reduced work productivity [10] and so forth. It has also been linked to much more grave conditions including diabetes [11] and many different forms of cancer [12]. Some of the most prevalent studies in this area are those linking breast cancer to artificial lighting exposure, especially during the night. The idea that artificial lighting may indeed be a concern in regards to breast cancer was given even more credit after a number of pioneering studies in this field showed breast cancer cases to be comparatively lower in blind women than in women with functioning eyesight $[13,14]$. Similarly, a couple of studies $[15,16]$, conducted in the US (United States) have shown correlations between high risk of breast cancer incidents and exposure to artificial lighting. The subjects for both studies were medical nurses who worked a minimum of three night shifts a month. In the first study [15], 78,562 such nurses were investigated in a 10-year follow-up. Based on data obtained from the investigation, statistical analysis showed that women who worked night shifts had a higher risk of developing breast cancer. In addition, the risk of developing breast cancer tended to increase with the number of years spent working night shifts; women who worked night shifts for more than 30 years showed a higher risk of developing breast cancer than women who worked night shifts for less than 29 years. In the second study, Schernhammer et al. [16] studied the relationship between rotating night shift work and the involved risk of developing breast cancer. 115,002 nurses were studied over a period of 12 years. The results revealed that high risk of breast cancer incidents is associated with longer periods of rotating shifts. Additionally, among 115,002 of the subjects who had no breast cancer at the beginning of the 12-year follow up, 1352 developed breast cancer during the time of the follow-up.

As evidenced through the existing literature, there is a potential link between light pollution and certain human health conditions. Concerns associated with light pollution have thus prompted a legal battle. A number of countries including Korea [17,18], France and Italy [19] have begun dictating lighting level limits through regulations in order to reduce the amount of light pollution. In places like Taiwan, light pollution research and policy is also becoming prevalent [20]. Additionally, concerned institutions such as the International Commission on Illumination (CIE) also offer general lighting recommendations for proper and sustainable usage of artificial lighting. In Korea, it has been 29 years since the Seoul municipal government installed outdoor lighting to celebrate the 1988 Seoul Olympic Games. Since then, artificial lighting at night has become common practice in cities all over Korea. Moreover, a recent series of controversies related to light pollution have sparked a number of debates in Korea. For this reason, it has become of vital importance that prior to planning and installing new lighting concepts, all parties involved have a firm understanding of the direct and indirect impact of artificial lighting on the surroundings. Additionally, while solutions are being developed, lighting guidelines and recommendations must be put in place so that light designers can create sustainably lit-environments at night with minimum risk of light pollution.

The aim of this paper is to present recent findings and discussions regarding light pollution and sustainable lighting. The assessment provided in this study is based on data gathered from field measurements conducted in Seoul, South Korea. Furthermore, the authors are of the view that close 
collaboration between architects and lighting designers at the conceptual stage of lighting projects is one way to reduce the current impact of excessive artificial lighting on the environment, while at the same time encouraging sustainable lighting.

\section{Restriction of Light Pollution}

The aim of light pollution laws is generally to permit reasonable usage of artificial lighting for safety, utility, and security, while minimizing the degradation of the nighttime visual environment and the night sky. Although countries and communities have different anti-pollution laws, light pollution regulations have three common main sections, namely, the classification of light pollution management zones, the establishment of standards and the provision of regulations.

Drafting laws that prevent excessive usage of artificial lighting and subsequently light pollution is not an easy task. Many questions arise when it comes to regulating light pollution. For instance, how to legally define light pollution or to what extent should artificial lighting be regulated? Without generally agreed upon solutions to such questions it becomes rather difficult to develop proper and effective legislation. The endeavors to develop regulations for light pollution reduction are also usually linked to questions of energy efficiency and or cityscape aesthetics [21]. Moreover, light pollution regulations should be simple and comprehensible to everyone. They should possess the advantage of simplicity, as they should not require in-depth knowledge of lighting. However, this also presents a disadvantage in that the laws are often relaxed, making it difficult to enforce. Morgan discusses the difficulty often faced while drafting light pollution legislation [22]. Below are some examples of the regulations in different nations and communities.

The illuminating engineering society and the International Dark-sky Association (IDA) joined together and established common regulations to be used as guidelines for preventing light pollution, the Model Lighting Ordinance [23]. The regulations recommend that fully shielded outdoor lighting be used at all times. They also advise that outdoor light fixtures have a control device/system that automatically turns off the light when sufficient daylight is available. Furthermore, the IDA regulations encourage the establishment of time limits after which the total lumens coming from outdoor lighting fixtures should be decreased by about $30 \%$ or lights turned off completely.

Korea is one of the most recent countries to enact a light pollution related law. The Korean government spent a period of 4 years, from September 2009 when the bill of the light pollution was submitted to the assembly to December 2011 when the bill was passed, debating all possible actions to prevent light pollution caused by excessive ALAN (Artificial Lighting At Night). As a result, the Light Pollution Prevention Act was enacted in February 2013. The prevention act was instated following a number of public complaints about light radiating from advertisement boards, streetlights, etc., trespassing into people's homes at night and disrupting their sleep patterns. The Korean Light Pollution Prevention Act breaks areas down into four environmental zones, which will herein after be referred to as Environmental Management Zones (E zones) [17]. The E zones range from E1, which covers the darkest areas, to E4, the brightest areas. The zones are categorized based on land use under the Korean law on National Land Planning and Use. Table 1a shows Environmental Management Zones presented by the CIE whereas Table $1 \mathrm{~b}$ shows Environmental Management Zones as established by the Light Pollution Prevention Act of South Korea. The idea behind the creation of Environmental Management Zones is that the levels of artificial lighting are not equally rigorous in all areas, thus the light disturbance diminution measures are not supposed to be equally stringent in all regions.

The Environmental Management Zones are divided into four zones [4] as shown in Table 1a. The zones labeled E1 to E4 describe natural, rural, suburban, and urban surroundings, respectively. Following this, the CIE provides lighting standards that are recommended for each of these four Environmental Management Zones [24]. The Korean government has established lighting regulations identical to those of the CIE. The Environmental Management Zones established by the South Korean Light Pollution Prevention Act are also dived into four zones and lighting recommendations are 
presented for each zone [25]. Figure 1 shows the Environmental Management Zones of Seoul City established based on the conducted field survey [26].

Table 1. Description of lighting environmental management zones.

\begin{tabular}{|c|c|c|c|}
\hline \multicolumn{4}{|c|}{ (a) Zones by CIE (Commission Internationale de l'Ecclairage), 2003} \\
\hline Zone & Surroundings & Lighting Environment & Examples \\
\hline E1 & Natural & Intrinsically dark & National parks or protected sites \\
\hline E2 & Rural & Low district brightness & Agricultural or residential rural areas \\
\hline E3 & Suburban & Medium district brightness & Industrial or residential suburbs \\
\hline E4 & Urban & High district brightness & Town centers and commercial areas \\
\hline \multicolumn{4}{|c|}{ (b) Zones by Korean Light Pollution Legislation, 2013} \\
\hline Zone & \multicolumn{3}{|c|}{ Descriptions } \\
\hline E1 & \multicolumn{3}{|c|}{ Green areas used for ecological purposes and wildlife protection } \\
\hline E2 & \multicolumn{3}{|c|}{ Green areas used for agricultural activities } \\
\hline E3 & \multicolumn{3}{|c|}{ Residential and semi-residential areas } \\
\hline E4 & \multicolumn{3}{|c|}{ Commercial and industrial zones } \\
\hline
\end{tabular}

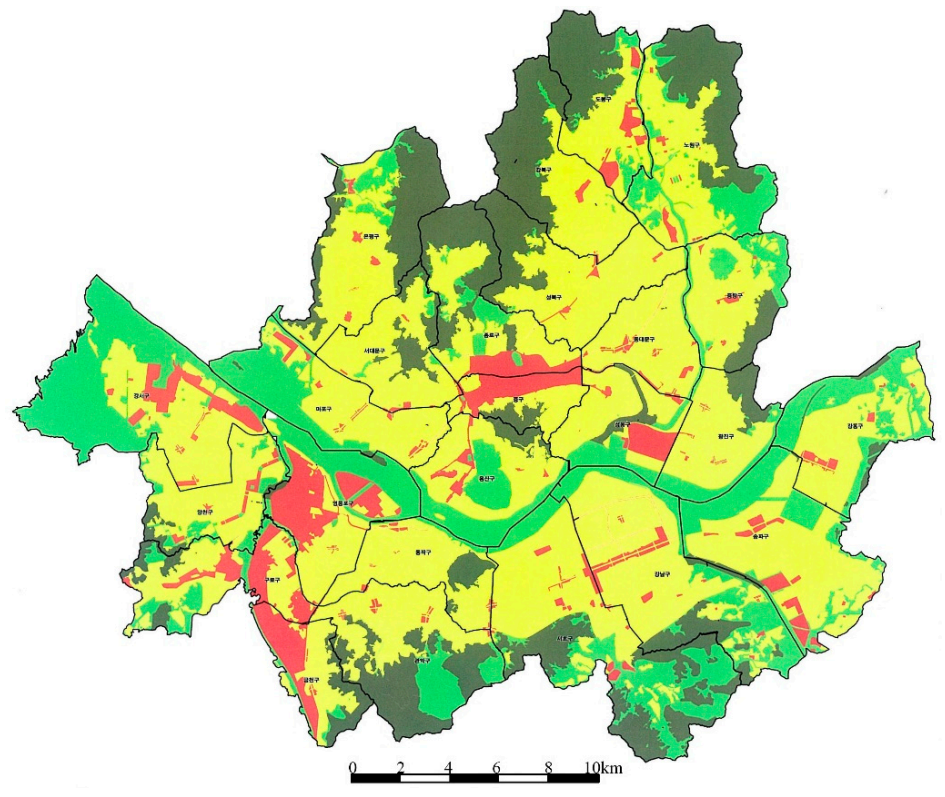

Figure 1. Environmental Management Zones of Seoul City, South Korea.

In addition to Environmental Management Zones, lighting standards make up a major part of light pollution prevention laws. Existing light pollution laws have focused on determining both the appropriate illuminance and luminance levels of artificial light that would cause minimum harm to the ecosystem. Standards for the prevention of light pollution give the light parameters values (mostly illuminance and luminance values) allowed in a given lighting Environmental Management Zone. Table 2 shows the lighting standards established by the CIE [4].

The lighting standards by the South Korean Light Pollution Prevention Law are very similar to those of the CIE. The two sets of standards differ only on minor details such as the degree to which light is limited in different environmental zones. Table 3 shows light recommendations by the South Korean Light Pollution Prevention Law. 
Table 2. Standards for light pollution by the International Commission on Illumination (CIE).

\begin{tabular}{lcccccc}
\hline \multirow{2}{*}{$\begin{array}{c}\text { Light Technical } \\
\text { Parameter (lux) }\end{array}$} & Light Technical & Application & \multicolumn{4}{c}{ Lighting Environmental Zones } \\
\cline { 3 - 7 } & Parameter (cd) & Conditions & E1 & E2 & E3 & E4 \\
\hline \multirow{2}{*}{ Vertical illuminance } & & Pre-curfew & 2 & 5 & 10 & 25 \\
& & Post-curfew & 0 & 1 & 2 & 5 \\
\hline & Luminous intensity & Pre-curfew & 2500 & 7500 & 10,000 & 25,000 \\
& & Post-curfew & 0 & 500 & 1000 & 2500 \\
\hline & Building façade luminance & No curfew & 0 & 5 & 10 & 25 \\
& Sign luminance & No curfew & 50 & 400 & 800 & 1000 \\
\hline
\end{tabular}

Table 3. Standards for light pollution in Korea.

\begin{tabular}{|c|c|c|c|c|c|c|c|}
\hline \multirow{2}{*}{ Category } & \multirow{2}{*}{ Parameter (lux) } & \multirow{2}{*}{ Parameter $\left(\mathrm{cd} / \mathrm{m}^{2}\right)$} & \multirow{2}{*}{ Time of Application } & \multicolumn{4}{|c|}{ Zones } \\
\hline & & & & E1 & E2 & E3 & E4 \\
\hline Roads and street & $\begin{array}{c}\text { Max. vertical } \\
\text { plane Illuminance }\end{array}$ & & $\begin{array}{l}60 \mathrm{~min} \text { after sunset to } 60 \mathrm{~min} \\
\text { before sunrise }\end{array}$ & 10 & 10 & 10 & 25 \\
\hline $\begin{array}{l}\text { Non-flashing } \\
\text { advertisement }\end{array}$ & & Max. luminance & $\begin{array}{l}60 \mathrm{~min} \text { after sunset to } 60 \mathrm{~min} \\
\text { before sunrise }\end{array}$ & 50 & 400 & 800 & 1000 \\
\hline \multirow{3}{*}{$\begin{array}{l}\text { Screen video } \\
\text { and Flashing }\end{array}$} & $\begin{array}{l}\text { Max. vertical } \\
\text { plane }\end{array}$ & & $\begin{array}{l}60 \mathrm{~min} \text { after sunset to } 60 \mathrm{~min} \\
\text { before sunrise }\end{array}$ & 10 & 10 & 10 & 25 \\
\hline & & \multirow{2}{*}{ Avg. luminance } & 60 min after sunset to $24: 00$ & 400 & 800 & 1000 & 1500 \\
\hline & & & $24: 00$ to $60 \mathrm{~min}$ before sunrise & 50 & 400 & 800 & 1000 \\
\hline \multirow{2}{*}{ Decorative } & & Avg. luminance & \multirow{2}{*}{$\begin{array}{l}60 \mathrm{~min} \text { after sunset to } 60 \mathrm{~min} \\
\text { before sunrise }\end{array}$} & 5 & 5 & 15 & 25 \\
\hline & & Max. luminance & & 20 & 60 & 180 & 300 \\
\hline
\end{tabular}

\section{Measurement of Light Pollution}

The nightscape in the modern environment is hugely made up of lit objects. From building lights that reveal architectural characteristics of high-rise buildings and bright advertisement signboards showcasing economic development, to security lights in residential neighborhoods and parks. As such, attention should be paid to the way lit environments are measured, and regular assessments of the luminous condition of lit areas should be conducted.

Lighting standards require an expert in the field of lighting since they are based on the quantification of light. The methods of measurement and analysis play a significant role in assessing a given environment for possible light pollution. As a visually luminous environment is a complex issue involving various elements such as lighting sources and luminous properties, measurements should be conducted accurately [27].

Generally, luminance measurements can be taken as point luminance measurements using luminance meters; however, this method has been disregarded due to its inaccuracy when measuring surface luminance emitted by light sources. As an alternative, aerial nighttime photography is being used to perform spatial nighttime artificial lighting analyses [21]. Similarly, using data capturing technologies, nighttime satellite images and maps are being utilized to develop spatial GIS database for sensitive suburban areas [28]. In addition, using radiative transfer methods in the propagation of light pollution, studies [29] have been able to review available indicators for quantifying and monitoring light pollution.

There also exist different methods that can be used to determine the quality and amount of light displayed within a given visual environment. Among the existing techniques, high dynamic range (HDR) imaging has been acknowledged by experts as the most efficient [30]. The luminous tone mapping technique has become popular recently as it can be used to simulate an accurate image of any lit environment to match the actual amount of light radiated within it. Moreover, advancements in computer technology have offered new ways of using the tone mapping technique to produce visual 
environment images as accurately as the human eye [31]. Figure 2 shows the luminous tone mapping technique that has become popular recently as it can be used to simulate an accurate image of any lit environment to match the actual amount of light radiated within it.

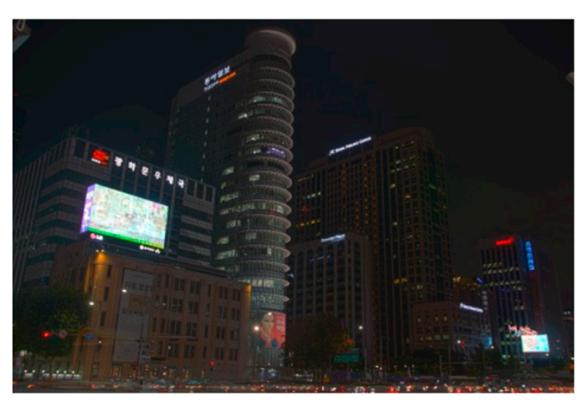

(a)

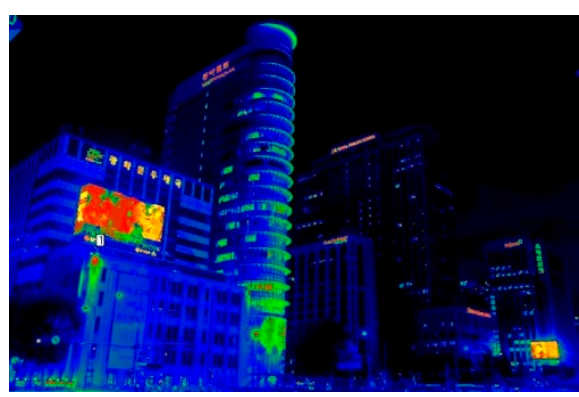

(b)

Figure 2. Digital image processing for the determination of light pollution: (a) Actual image of a billboard sign; (b) Analysis image using light measuring camera (LMK) lab soft.

Until recently in Korea, there was no scientific method to obtain quantitative light pollution data. A drive towards quantitative measurement accompanied the enactment of the Light Pollution Prevention Act. The National Institute of Environmental Research of Korea (NIERK) has established a prototype measurement method for determining light pollution from a lighting source. This method of lighting evaluation considers possible enhancements of landscapes at night while at the same time facilitating visual safety and reducing light pollution. The method assesses the quantity of light through reducing the measurement target to either an individual point or a target surface. In so doing, it allows the consideration of distance and measuring angle in the evaluation of light pollution $[27,30]$.

For this study, simple hand-held tools such as the Chroma Meter CL-200A and LMK Luminance Meter were utilized. The former for the measurement of vertical plane illuminances and the latter for the measurement of surface luminance levels. The process involved in measuring vertical illuminances on areas adjacent to lighting sources is quite simple and straightforward. The CL-200A meter has to be held in a vertical position onto a surface adjacent to the lamp being assessed for light-trespass such as a window on a building facade. The meter will then read out the number of lumens falling onto a single unit of the surface. The resulting element, lumen per square meter is what is known as illuminance and is mostly presented with "lux" as a unit.

The process involved in obtaining surface or point luminance however is a bit more sophisticated. The Luminance Meter camera uses the High Dynamic Range (HDR) technology. It works in a way that several low dynamic images of an illuminated surface are taken at different exposure times (shutter speeds). These images are then combined into one but richer image referred to as an HDR image. This final image is what is used together with a computer software to extract minimum and maximum luminance levels of the surface being analyzed [27]. The software program also gives an option of extracting luminance of the entire surface or single specific points of interest on the surface, for example a billboard sign mounted on a building facade. In this study, we used a light measuring camera (LMK), developed by Techno Team, for capturing images and LMK lab software to analyze the images.

To improve accuracy in the measurement of luminance levels, a method developed by the National Institute of Environmental Research of Korea was utilized. The method involves subtracting the luminance of the background field from the luminance of the target area and multiplying by a weighting factor of 0.9 to give an accurate luminance value dissipated by target area [32].

In addition, the Korean Light Pollution Prevention Act provides other guidelines for conducting the measurement procedure. For instance, the measurements are to be taken in the absence of severe weather conditions such rain or snow. This is because weather elements might amplify or lessen the effect of lighting parameters measured by simple equipment. Secondly, for the measurement of 
luminance values using light-mapping cameras, measurements are to be taken parallel to the light source being assessed. If it is impossible to capture full images due to obstacles, images are to be taken at angles between 0 and 30 degrees. In addition, the camera should be positioned in a manner that the vertical height between the ground and the camera is at least $1.5 \mathrm{~m}$. All these suggestions by the Korean Light Pollution Prevention Act were followed in the assessment of light pollution discussed in the current study.

\section{Field Study of Light Pollution in Seoul City}

Since the Light Pollution Prevention Act was enacted, robust field studies were conducted in Seoul City regarding the probable effects of light pollution. The principal purpose for conducting light pollution measurements in Seoul, Korea, was to determine the current nature of artificial lighting usage in Seoul City, and thus obtain a starting point for tackling its effects. The measurements primarily considered the main contributors of artificial lighting in modernized urban environments. Specifically, the investigation was to measure the extent to which light radiated from space lighting (i.e., security and street lighting) and advertisement lighting exceeded the lighting levels dictated by the Light Pollution Prevention Act. The investigation was carried out based on the Environmental Management Zones.

Field measurements were conducted in more than 300 locations. The amount of excessive lighting was measured to collect more data on the sources of light pollution. In Seoul, the areas to be investigated were chosen based on the number of public complaints (starting with the highest), high-lit areas, and areas expected to cause the most severe forms of light pollution. These field studies were then used as key guidelines for improving the regulations and standards that had earlier been established into a dedicated law by the Korean government. The Seoul City case project is used as an example of how measurements were conducted to investigate light pollution caused by light trespass, decorative lighting, and advertisement lighting [26].

\subsection{Space Lighting and Light Trespass}

Space lighting consists of street and security lighting. Light radiating from both these sources was measured in E3, which consists mainly of residential areas. The lighting fixtures that were targeted in the residential areas were those in close proximity with building facades and thus most likely to cause disturbance to building occupants. The light component measured was vertical illuminance, which was measured at a distance between the lamppost and the building façade. For better assessment, measurements were taken at the brightest spots of the first-floor windows, before and after the lights were turned on. For street lighting, measurements were conducted on walkways and city squares in E4, which consists mainly of business district.

The results from the field survey on space lighting in E3 showed that, $67 \%, 70 \%$, and $86 \%$ of the street and security lighting exceeded the recommended vertical luminance values in residential, semi-residential, and industrial areas respectively. The survey on space lighting found in E4 showed that $5 \%$ of space lighting in semi-residential areas and $36 \%$ of space lighting in industrial areas exceeded the vertical luminance values dictated by the law.

In the target areas investigated for light pollution caused by space lighting $67 \%, 70 \%$, and $86 \%$ of the street and security lighting exceeded the recommended vertical luminance values in residential, semi-residential, and industrial areas located in E3, respectively. Similarly, 5\% and 36\% of space lighting in semi-residential and industrial areas, respectively, located in E4 exceeded the vertical luminance values dictated by the law. Figure 3 shows the ratio of areas with space lighting exceeding the recommended lighting limits.

In addition, the types of luminaires were also considered in order to determine the light types that were responsible for causing the maximum amount of light pollution. The luminaire types found in the target areas were ceramic metal halide (CMD), Natrium Halide (NH), Metal Halide (MH), and Light Emitting Diodes (LED). The results of the investigation show that $88 \%$ of installed CMD, 
$70 \%$ of installed $\mathrm{NHs}, 47 \%$ of MHs, and $13 \%$ of LEDs radiated light that exceeded the recommended lighting limits.

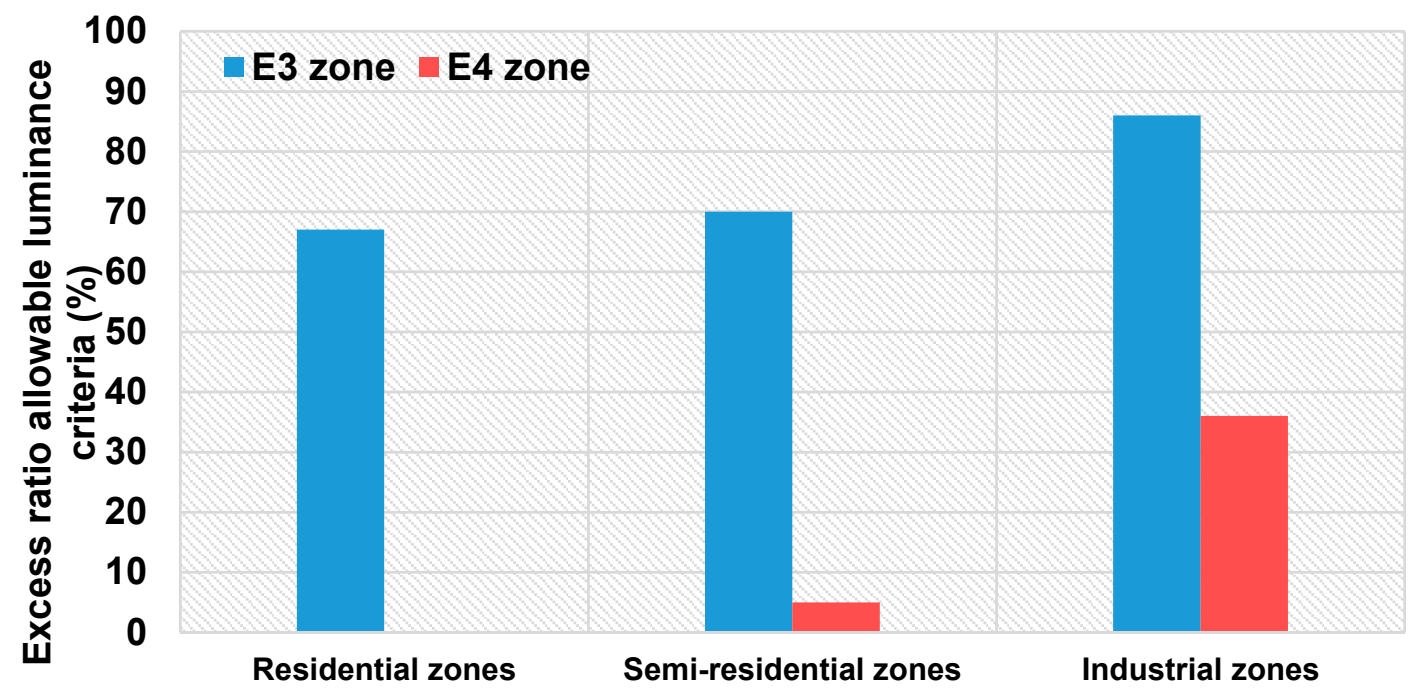

Figure 3. Ratio of areas with space lighting exceeding the recommended lighting limits.

\subsection{Advertisement Lighting and Luminance}

Lighting belonging to advertisement billboards in commercial districts, as well as decorative lighting, also appeared to play a significant role in light pollution related complaints from people residing in these areas. As such, they were a huge part of the investigation. The obtained values were then compared with the allowed luminance values to gauge the extent to which advertisement companies and individual businesses were exceeding the recommended limit of light luminance. In addition, the types of lighting being used in advertisement lighting, such as the channel letter, flux, neon lights, etc., were considered in order to determine which of the light types were responsible for the largest spread of light pollution. Figure 4 shows the ratio of areas with advertisement lighting exceeding the recommended lighting limits.

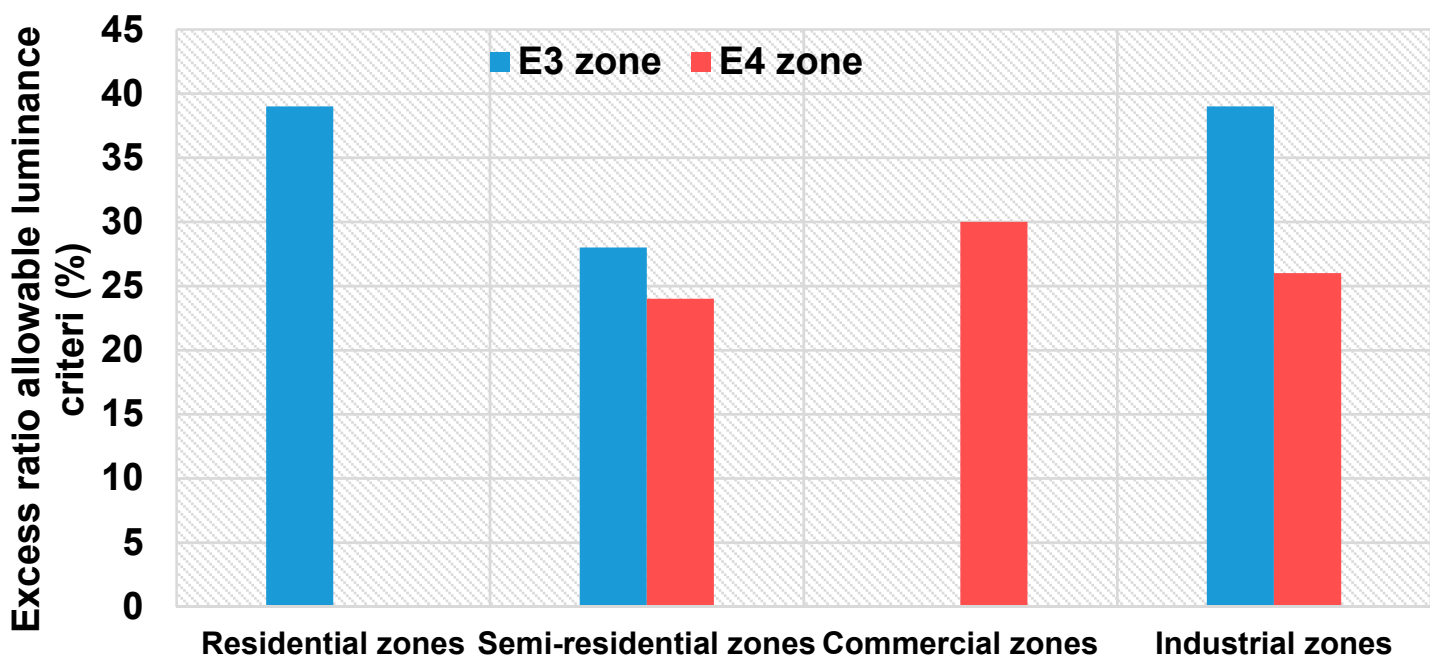

Figure 4. Ratio of areas with advertisement lights exceeding allowed lighting limits.

For advertisement lights, residential, semi-residential, and industrial areas located within E3 had $39 \%, 28 \%$, and $26 \%$, respectively, of the installed advertisement lights exceeding the limit values. 
In addition, $24 \%$ of advertisement lights in semi-residential areas, $30 \%$ of advertisement lights in commercial areas, and $26 \%$ of the advertisement lights in industrial areas located within E4 exceeded the surface luminance values.

\subsection{Decorative Lighting and Luminance}

Regarding the number of decorative lights with surface luminance exceeding the allowed values in the investigated areas, $86 \%, 100 \%$, and $56 \%$ of the decorative spaces in residential, semi-residential, and industrial areas, respectively, in E3 had higher luminance values than those dictated by the law. Correspondingly, $88 \%$ of semi-residential areas, $72 \%$ of commercial areas, and $44 \%$ of industrial areas located within E4 exceeded the lighting limits allowed. Figure 5 shows the ratio of areas with decorative lighting exceeding the recommended lighting limits.

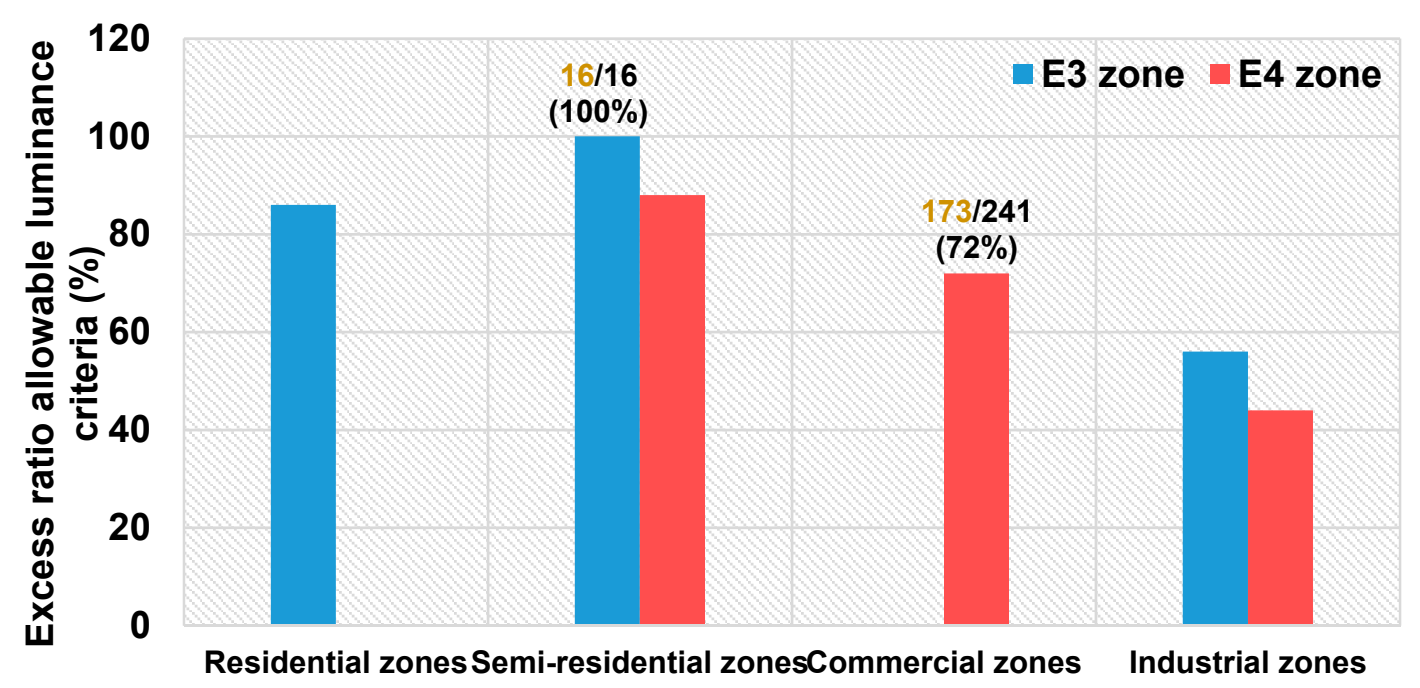

Figure 5. Ratio of areas with decorative lighting exceeding recommended lighting limits.

\section{Discussion and Conclusions}

The continuous increase in nighttime outdoor lighting and its effects on the environment have recently been receiving vast amounts of attention. This has corresponded to an increase in the demand for solutions. This paper has provided an extensive discussion on light pollution, emphasizing the related issues, standards, and legislation. This study also presented assessments of real case studies in urban environments. The findings can be summarized as follows.

As evidenced through the literature, excessive light at night interferes with the production of the melatonin, and has been linked to the increased risk of cancer, diabetes, and obesity. As such, light pollution has become a serious issue facing humanity. Luminaires chosen and the degree to which they distribute light should be considered carefully before the installation of any light fixtures. Additionally, it is also important to point out that, new lighting technologies do not necessarily offer better alternatives in regards to the control of light pollution. A good example of such a technology is the light—emitting diodes (LEDs). Governments and municipalities around the world are readily replacing traditional lamps with LEDS in streets and general industrial usage; this is done largely because of the potential shown by LEDs to save energy. However, as discussed by Pawson and Bader [33], white LEDs are more likely to have negative impacts on natural ecosystems than high-pressure sodium (HPS) vapor lamps.

Light pollution prevention standards and regulations should be given equal weight for the efficient eradication of the effects of artificial lighting at night. The results from real surveys conducted in Seoul, South Korea, show that a large proportion of the investigated areas exceeded the lighting limits dictated by the Korean Light Pollution Prevention Act. In most cases, all chosen sample spots 
exceeded the lighting limits allowed in their respective lighting environmental management zones. Moreover, most of the luminaires that were being used in Seoul were found to be outdated, in terms of lighting technology, and were found to be responsible for the spread of light pollution and causing setbacks to sustainable lighting; this however does not mean that newer lighting technologies are not a cause of light pollution. Extensive research in this area seems rather necessary. The assessments conducted also show that there have not been any reductions in light pollution despite the enactment of the law against light pollution. As such, a robust strategy that would reinforce the light pollution law, not only in Seoul but also in other regions of South Korea, is of crucial necessity.

Author Contributions: Hong Soo Lim and Jack Ngarambe participated in the process of measuring data, analysis of the luminous environment, and documentation of the study. Jeong Tai Kim conducted the project as the principal investigator and pushed the light pollution issues in parallel with the policy advances to draw conclusion. Gon Kim led the construction of the manuscript and his academic skill on both lighting pollution and assessment provided the knowledge on how to measure the luminous data and evaluate the illuminated environment in the study.

Conflicts of Interest: The authors declare no conflict of interest.

\section{References}

1. Hollan, J. What is light pollution, and how do we quantify it? 7th European Symposium for the Protection of the Night Sky-Light Pollution and Global Warming. In Proceedings of the Workshop Paper at Darksky 2007 Conference, Brno, Czech Republic, 5-6 October 2007.

2. What is Light Pollution? Available online: http://www.darksky.org/light-pollution/ (accessed on 24 January 2018).

3. Seoul Metropolitan Government Enforcement Rule of the Ordinance on the Prevention of Light Pollution and Management of Formation of Good Light. Available online: http://legal.seoul.go.kr/legal/english/ front/page/law.html?pAct=lawView\&pPromNo=1442 (accessed on 24 January2018).

4. Narisada, K.; Schreuder, D. Light pollution and astronomy. In Light Pollution Handbook; Springer: Amsterdam, The Netherlands, 2004; pp. 115-138.

5. Liu, M.; Zhang, B.G.; Li, W.S.; Guo, X.W.; Pan, X.H. Measurement and distribution of urban light pollution as day changes to night. Light. Res. Technol. 2017. [CrossRef]

6. Kent, M.G. Temporal Effects in Glare Response. Ph.D. Thesis, University of Nottingham, Nottingham, UK, 2016.

7. Touitou, Y.; Reinberg, A.; Touitou, D. Association between light at night, melatonin secretion, sleep deprivation, and the internal clock: Health impacts and mechanisms of circadian disruption. Life Sci. 2017, 193, 94-106. [CrossRef] [PubMed]

8. Sugden, D. Melatonin biosynthesis in the mammalian pineal gland. Cell. Mol. Life Sci. 1989, 45, 922-932. [CrossRef]

9. Weinert, D.; Waterhouse, J. Interpreting Circadian Rhythms. In Biological Timekeeping: Clocks, Rhythms and Behaviour; Springer: New Delhi, India, 2017; pp. 23-45.

10. Bermudez, E.B.; Klerman, E.B.; Czeisler, C.A.; Cohen, D.A.; Wyatt, J.K.; Phillips, A.J. Prediction of vigilant attention and cognitive performance using self-reported alertness, circadian phase, hours since awakening, and accumulated sleep loss. PLoS ONE 2016, 11. [CrossRef] [PubMed]

11. Hu, C.; Jia, W. Linking MTNR1B variants to diabetes: The role of circadian rhythms. Diabetes 2016, 65, 1490-1492. [CrossRef] [PubMed]

12. Bishehsari, F.; Levi, F.; Turek, F.W.; Keshavarzian, A. Circadian Rhythms in Gastrointestinal Health and Diseases. Gastroenterology 2016, 151, e1-e5. [CrossRef] [PubMed]

13. Feychting, M.; Österlund, B.; Ahlbom, A. Reduced cancer incidence among the blind. Epidemiology 1998, 1 , 490-494. [CrossRef]

14. Kliukiene, J.; Tynes, T.; Andersen, A. Risk of breast cancer among Norwegian women with visual impairment. Br. J. Cancer 2001, 84, 397-399. [CrossRef] [PubMed]

15. Schernhammer, E.S.; Laden, F.; Speizer, F.E.; Willett, W.C.; Hunter, D.J.; Kawachi, I.; Colditz, G.A. Rotating night shifts and risk of breast cancer in women participating in the nurses' health study. J. Natl. Cancer Inst. 2001, 93, 1563-1568. [CrossRef] [PubMed] 
16. Schernhammer, E.S.; Kroenke, C.H.; Laden, F.; Hankinson, S.E. Night work and risk of breast cancer. Epidemiology 2006, 17, 108-111. [CrossRef] [PubMed]

17. Cha, J.S.; Lee, J.W.; Lee, W.S.; Jung, J.W.; Lee, K.M.; Han, J.S.; Gu, J.H. Policy and status of light pollution management in Korea. Light. Res. Technol. 2014, 46, 78-88. [CrossRef]

18. Ko, T.K.; Kim, I.T.; Choi, A.S.; Sung, M.K. Quantitative assessment methods for determining luminous environmental zones in Korea. Light. Res. Technol. 2016, 48, 307-322. [CrossRef]

19. Morgan-Taylor, M. Regulating light pollution in Europe: Legal challenges and ways forward. In Urban Lighting, Light Pollution and Society; Routledge: Abingdon, UK, 2015.

20. Ho, C.Y.; Lin, H.T. Analysis of and control policies for light pollution from advertising signs in Taiwan. Light. Res. Technol. 2015, 47, 931-944. [CrossRef]

21. Krop-Benesch, A.; Kyba, C.; Hölker, F. ALAN 2013-First International Conference on Artificial Light at Night: Abstracts; Universitätsverlag der TU Berlin: Berlin, Germany, 2015.

22. Morgan-Taylor, M.; Kim, J.T. Regulating Artificial Light at Night: A Comparison between the South Korean and English Approaches. Int. J. Sustain. Light. 2016, 35, 21-31. [CrossRef]

23. Joint, I.D. Model Lighting Ordinance (MLO) with User's Guide; Second Public Review; Illuminating Engineering Society: New York, NY, USA, 2010.

24. Remande, C. Light Pollution: How High-Performance Luminaires Can Reduce It. Symposium-International Astronomical Union; Cambridge University Press: Cambridge, UK, 2001; Volume 196, pp. 49-59.

25. Kim, K.T.; Oh, M.S.; Kim, H.S. A Study on the Control Standards and an Environmental Lighting Zone-Setting method for Making Light Pollution Management. J. Korean Inst. Illum. Electr. Install. Eng. 2011, 25, 27-33. [CrossRef]

26. Seoul Solution. Available online: https://www.seoulsolution.kr/en/node/6559 (accessed on 22 November 2015).

27. Kim, G.; Amina, I.; Lim, H.S.; Kim, J.T. The Impact of Distance on the Accuracy of Luminance Measurement. Energy Procedia 2014, 62, 612-618. [CrossRef]

28. Chalkias, C.; Petrakis, M.; Psiloglou, B.; Lianou, M. Modelling of light pollution in suburban areas using remotely sensed imagery and GIS. J. Environ. Manag. 2006, 79, 57-63. [CrossRef] [PubMed]

29. Cinzano, P.; Falchi, F. Quantifying light pollution. J. Quant. Spectrosc. Radiat. Transfer 2014, 139, 13-20. [CrossRef]

30. Lim, H.S.; Kim, J.T.; Kim, G. Comparative verification of high dynamic range image tools for luminous analysis of visual environment. Indoor Built Environ. 2014, 23, 107-117. [CrossRef]

31. Ward, G.; Simmons, M. Subband encoding of high dynamic range imagery. In Proceedings of the 1st Symposium on Applied Perception in Graphics and Visualization, Los Angeles, CA, USA, 7 August 2004; pp. 83-90.

32. Standard for measuring Light Pollution (ES1100.a). Available online: http:/ / www.nier.go.kr/NIER/cop/bbs/ selectNoLoginBoardList.do?bbsId=BBSMSTR_000000000241\&menuNo=15004 (accessed on 25 January 2018).

33. Pawson, S.M.; Bader, M.F. LED lighting increases the ecological impact of light pollution irrespective of color temperature. Ecol. Appl. 2014, 24, 1561-1568. [CrossRef] [PubMed]

(c) 2018 by the authors. Licensee MDPI, Basel, Switzerland. This article is an open access article distributed under the terms and conditions of the Creative Commons Attribution (CC BY) license (http:/ / creativecommons.org/licenses/by/4.0/). 